\title{
Descaminhos do método* notas sobre história e tradição em Hans-Georg Gadamer
}

\author{
Wayless methods: \\ notes about history and tradition in Hans Georg Gadamer
}

\author{
NORMA CÔRTES \\ Professora Adjunta de Teoria e Metodologia da História \\ IFCS/UFRJ - Universidade Federal do Rio de Janeiro \\ Largo de São Francisco, 1, Centro, Rio de Janeiro, 20051-070 \\ ncortes@ifcs.ufr..br
}

RESUMO A partir de Verdade e Método, este artigo analisa a historicidade da atitude epistêmica e do método científico, explorando alguns aspectos envolvidos no estatuto prudencial do conhecimento histórico tal como estabeleceu a obra de Gadamer.

Palavras-chave Hermenêutica, historicidade, método histórico, ciência e phronesis

ABSTRACT Drawing on Truth and Method, this article examines the historicity of the epistemic position and of the scientific method, and explores some aspects of the prudential statute of historical knowledge as established in Gadamer's work.

Key words Hermeneutics, historicity, historical method, science and phronesis

Artigo recebido em 04/08/2005. Autor convidado. 
a alma mais forte' do precedente maior, a proximidade da versão rival, a existência, a um só tempo opressiva e libertadora, de uma tradição comum, liberta o escritor da armadilha do solipsismo. Um pensador ou artista verdadeiramente original é simplesmente o que excede ao pagar suas dívidas.

George Steiner $^{1}$

\section{1.}

Verdade e Método. Fundamentos de uma hermenêutica filosófica² é a mais importante obra de Hans-Georg Gadamer (1900-2002). Publicada primeiramente em 1960, ela se inscreve nos debates sobre a crise das idéias de consciência e de representação mental do mundo, sendo herdeira da mesma tradição filosófica que ultrapassou os impasses do solipsismo cartesiano para além do transcendentalismo de Kant e fixou os termos dessa virada intelectual que marcou o século XX. ${ }^{3}$ Obra de maturidade, foi escrita após Gadamer ter lecionado por mais de dez anos na Universidade de Heidelberg várias disciplinas filosóficas sobre os clássicos e a história das chamadas ciências do espírito ${ }^{4}$ reconstituindo uma senda que, remotamente, foi inaugurada no dualismo racionalista de Immanuel Kant (1724-1804); atravessou a hermenêutica de Friedrich Schleiermacher (1768-1834); e, a partir daí, percorreu os caminhos da filosofia do espírito de G.W.F. Hegel (1770-1831); do historicismo de Wilhelm Dilthey (18331911); das meditações neocartesianas de Edmund Husserl (1859-1938); da fenomenologia do saber de Max Scheler (1874-1928); assumiu a tônica weberiana do existencialismo de Karl Jaspers (1883-1969); e por fim chegou até a investida ontológica de Martin Heidegger (1889-1976). ${ }^{5}$ Verdade

STEINER,George. Depois de Babel: questões de linguagem e tradução. Curitiba: Editora da UFRP, 2005, p 482.

2 Atenção. Nestas notas, adoto as seguintes abreviaturas para referir às obras de Gadamer: AA (1977) Meus anos de aprendizagem; CH (1956) O problema da consciência histórica; VM (1960) Verdade e Método; VMc (1943-1983) Verdade e Método.Complementos e índices. As referencias bibliográficas completas estão no fim do artigo.

3 "Verdade e Método teve, desde 1960, uma enorme eficácia sobre o desenvolvimento da filosofia, como por exemplo, na marcada orientação para a linguagem, onde o continente se encontrou com o 'linguistic turn' da filosofia anglo-saxônica; depois, na reabilitação da filosofia prática, primeiro na forma de um retorno a m novo aristotelismo, que complementou a ética kantiana do dever com uma consideração da contingência histórica de formas de vida; mas também na teoria científica, onde o contextualismo paradigmático de Kuhn podia saudar um jurado auxiliar na crítica do positivismo pela hermenêutica. E, finalmente, no refinamento da consciência hermenêutica para as tarefas de uma teoria crítica da sociedade, abstraindo totalmente de aplicações científicas particulares da hermenêutica no âmbito da ciência literária (que motivou H.R. Jauss e W. Iser a uma concretização da dialética da pergunta e resposta, na forma de uma estética da recepção), na História, (R. Kosellek), no direito e na Teologia." GRONDIN, Jean. Introdução à hermenêutica filosófica. São Leopoldo: Editora UNISINOS, 1999, p 208. Cf. também DELACAMPAGNE, Christian. História da Filosofia no século XX. Rio de Janeiro: Jorge Zahar, 1997.

4 No imediato pós-guerra, ele permaneceu do lado oriental e somente em junho de 1950, depois de muita peripécia, mudou-se para Heidelberg onde sucedeu a Karl Jaspers. Desde então, ofereceu vários seminários temáticos sobre a História da filosofia e das ciências do espírito. Ver a listagem de suas atividades docentes em Jean GRONDIN. Hans Georg Gadamer: una biografia. Barcelona: Herder, 2000, p 461-481.

5 Cf. CÔRTES, N. Fatos, fontes e frutos de uma tradição filosófica. Cronologia bibliográfica selecionada. Disponível em Artes do Tempo www.artesdotempo.hpg.com.br. 
e Método nasceu, portanto, com o caráter de obra síntese. ${ }^{6}$ Ela encerra o processo histórico de composição de uma longa e consistente tradição filosófica que se notabilizou tanto por sua atitude teorética crítica e reflexiva; quanto pelo acento temporal que paulatinamente conferiu à singularidade do mundo histórico e à historicidade da razão; e consequentemente (em decorrência de ambos esses aspectos) em virtude também da crescente autoconsciência histórica acerca do desenrolar de toda essa mesmíssima trajetória de alteração cognitiva e intelectual.

Herdeira e intérprete dessa tradição, a obra de Gadamer é uma peça filosófica que contém múltiplas atitudes autorais, sendo analítica e teorética - histórica e tética. ${ }^{7}$ Essa abordagem mista permitiu que o autor, em um só fôlego, resgatasse a trajetória histórica dessa linhagem de pensadores, narrando seus debates desde a chamada "virada epistemológica" até o giro hermenêutico de inspiração heideggeriana; recuperasse analiticamente tal tradição de pensar rendendo-Ihe todas as homenagens; e concreta e efetivamente se instalasse em uma situação cognitiva caracterizada por filial reconhecimento histórico e atualização filosófica (eis a situação hermenêutica). Todos esses procedimentos teóricos não apenas desafiaram os cânones argumentativos da história das idéias ${ }^{8}$ e dos enfadonhos tratados metodológicos, como, principalmente, evidenciavam um zeloso esforço ${ }^{9}$ para investigar o problema da compreensão hermenêutica ${ }^{10}$ e estabelecer o estatuto epistêmico dessa forma de inteligência além dos limites das ciências ou do método. Gadamer rejeitou a pretensão de indubitabilidade da metodologia científica ${ }^{11}$ e explorou os domínios da arte, das ciências do

6 Eis os primeiros comentários de Hans Albert em carta endereçada a Paul Feyerabend: "Acabo de leer el voluminoso libro de Gadamer, Verdad y Método (500 páginas). No quiero decir: ni verdade ni método, aunque esto se podria defender hasta cierto punto. Parece ser la Bíblia de la actual filosofia ('hermenéutica') alemana." Apud GRONDIN, Jean. idem, p 375.

7 Trata-se de atitudes autorais e filosóficas distintas. Enquanto as duas primeiras envolvem especulação, exame e reflexão críticos, as duas seguintes remetem ao âmbito das realizações acontecimental e histórica ou fenomenológica.

8 Sobre paradigmas historiográficos em História das Idéias, entre outros, cf.: DOSSE, François. La marche dês idées. Histoire dês intellectuels — histoire intellectuelle. Paris: La Découverte, 2003

9 Seu caráter de obra construída laboriosa e vagarosamente é nitidamente percebido a partir da leitura de $\mathrm{CH}$, livro de 1956 que antecipa partes do argumento central de VM, e também do seu segundo volume, VMc. Lançado em 1986, VMc reúne vários textos anteriores e posteriores a 1960, cobrindo um extenso período de produção intelectual entre os anos 1945 até 1985. Dessa forma, permite mapear várias gerações intelectuais: primeiro, descrevendo as inclinações e o desenvolvimento do pensar gadameriano antes da publicação de VM e, depois, reunindo as muitas réplicas dadas à recepção critica da obra. Trata-se de um belo volume, pois confirma a definição de CALVINO, Ítalo do que é um clássico: "Clássico é uma obra que provoca incessantemente uma nuvem de discursos críticos sobre si, mas continuamente as repele para longe." Por que ler os clássicos. São Paulo: Companhia das Letras, 1993, p 12.

10 Hermenêutica é a arte de compreender, interpretar e traduzir o sentido "exato" do um texto. A palavra alude a Hermes, divindade grega que mantinha a comunicação entre o Olimpo e os mortais traduzindo a linguagem dos deuses para o mundo dos homens e vice-versa. (Cf VMc, p 112). Segundo Richard Palmer, ela possui três significados: dizer/anunciar; explicar; traduzir. Mas em qualquer dessas acepções trata-se de transferir uma dada mensagem estabelecendo a mediação entre dois mundos, planos ou domínios (isto é: entre os tempos presente e passado; de um idioma para outro; do divino para o humano etc.) PALMER, Richard E. Hermenêutica. Lisboa: Edições 70, 1999.

11 En realidad hay muchas formas de certeza. Aquélla que se busca a través de un cercioramiento pasado por la duda es distinta de esa certeza vital inmediata de que se revisten todos los objetivos y valores de la conciencia humana cuando elevan una pretensión de incondicionalidad. Pero aún hay que distinguir mejor de esta certeza alcanzada en la vida misma aquélla que es propia de la ciencia. La certeza científica tiene siempre un rasgo cartesiano. Es el resultado de una metodología crítica que intenta retener sólo lo indudable. En este sentido esta 
espírito e da linguagem, identificando outros territórios onde tradicionalmente se encerram modos de expressão não-representacionais ${ }^{12}$ da verdade. No núcleo de Verdade e Método pulsa uma especulação filosófica: qual a morada da verdade?

Tributária de Ser e Tempo (1927), ${ }^{13}$ essa questão ganhou novo alcance e tratamento através da hermenêutica gadameriana. E antes de consistir em um problema de adequação entre as palavras e as coisas, a verdade em Gadamer aparece como aletheia. Entretanto, ao contrário de Heidegger, para quem aletheia é clareira e des-velamento (expressões cercadas por um halo impreciso ${ }^{14}$ ), em Verdade e Método, a verdade traduz-se literalmente como "des-esquecimento".

Explico-me.

Palavra grega composta pelo prefixo de negação "a" agregado ao substantivo léthe (esquecimento), aletheia é a negação do esquecimento. Ela sugere a habilidade de avançar na contra mão da correnteza do rio dos mortos, o Lethes, desfazendo os caminhos do apagamento da memória. Seu sentido, portanto, não é o de ser subitamente assaltado por uma lembrança. Mas envolve o lento e trabalhoso esforço de "des-esquecer", isto é, o esforço de contrariar o fluxo temporal para resgatar do reino dos esquecidos todos os que merecem e devem ser recordados (entendido aqui também na acepção de acordados, despertados). Para Gadamer, a aletheia descreve a trajetória em que a anamnese se desfia. Porém, longe de ser uma faculdade anímica ou metafísica (tal como em Platão ${ }^{15}$ ), esse percurso realiza-se efetivamente em um continuum histórico como linguagem transmitida temporalmente que validou, confirmando ou rejeitando, os diversos esforços compartilhados pelos homens para viver-compreender a realidade do mundo. Quer dizer, ela se expressa como história, tempo, tradição. E exatamente por isso é senhora de várias moradas, pois conheceu no tempo as múltiplas formas do seu ser.

certeza no procede de la duda y su superación, sino que se adelanta desde un principio a la posibilidad de sucumbir ala duda. Así como en Descartes y su conocida meditación sobre la duda se propone una duda artificial e hiperbólica como un experimento que lleve al fundamtum inconcussum de la ciencia, la ciencia metódica pone en duda fundamentalmente todo aquello sobre lo que es posible dudar, con el fin de llegar por esta camino a resultados seguros. VM, p 300.

12 A literatura acerca do debate sobre o problema da verdade como representação mimética é vastíssima, entre outros, cf: RORTY, Richard. Philosophy and the mirror of nature. New Jersey: Princeton University Press, 1979. Ver também CARDOSO, C. e MALERBA, J. (org) Representações: contribuições a um debate transdisciplinar. Campinas, SP: Papirus, 2000.

13 As relações entre Gadamer e Heidegger foram marcadas por doses desmedidas de admiração, reconhecimento e silêncios. Em sua autobiografia, a figura de Heidegger é uma presença impregnante sendo invariavelmente mencionada com uma deferência que mistura humor e assombro. Cf. GADAMER, AA., passim. Ver também GADAMER. Heidegger's ways. Albany: State University of New York Press, 1994. Sobre diversos tipos de vínculos e filiações intelectuais (particularmente Husserl e Heidegger) cf. George STEINER. Lições dos mestres. .Rio de Janeiro: Record, 2005

14 Sobre o problema da verdade em Heidegger, cf.: Michael INWOOD. Dicionário Heidegger. Rio de Janeiro: Jorge Zahar, 2002.

15 Na filosofia platônica, a anamnese ou reminiscência é uma das provas da imortalidade da alma e constitui a única fonte do conhecimento verdadeiro. J. Ferrater MORA. Diccionario de Filosofia. Barcelona: Ariel, 1994. 


\section{2.}

Embora recusasse atribuir estatuto científico metódico à compreensão hermenêutica, Gadamer não se aproximou de qualquer forma de anarquismo metodológico. ${ }^{16}$ Antes, o fundamento dessa recusa repousa sobre um postulado de matriz historicista e fenomenológica que inscreve o fenômeno da compreensão no mundo da vida e nas experiências ordinárias que os homens normalmente travam entre si. ${ }^{17}$ Para o autor, a compreensão não envolve nenhuma forma de crítica à razão pura, prática ou histórica e, nesse sentido, também não exige uma teoria do conhecer (uma epistemologia) simplesmente porque consiste em um fenômeno existencial. Ou melhor, nossos esforços compreensivos não se estabelecem ou são fundados pela contemplação teorética, mas estão já e sempre dados como gestos mundanos (entenda-se: ordinários, comuns, cotidianos) do ser-no-mundo. Para Gadamer — trata-se de visão comum à sua linhagem de pensadores —, viver e compreender são uma e a mesma coisa. O que significa que o chamado mundo (ou a realidade) não consiste em um princípio envolvente, tal qual um continente inclusivo repleto de conteúdos animados ou inertes. Pois, a despeito da tangibilidade dos seus seres e haveres, a realidade do mundo é constituída dialógica e temporalmente. Em outras palavras, antes de ser um pólo objetal anteposto a sujeitos contemplativos, o mundo resulta dos esforços compartilhados, interativos e auto-interpretativos (hermenêuticos) dos seus agentes constituintes. Ele não se exibe simplesmente como um agregado caótico de entes substantivos, mas revela-se e é laboriosamente construído em uma espécie de contrato ontológico perenemente negociado ${ }^{18}$ que, ao predicar suas propriedades - através de um acordo conflituoso que distingue o certo e o errado, o falso e o verdadeiro, o meu e o teu, o bem e o mal, a obediência e o mando, o sujo e o limpo etc. - - define e estabelece tudo aquilo que é.

16 "A práxis de uma ciência viva [...] não é mera aplicação de um saber e de métodos a um objeto qualquer. Só quem adota a perspectiva de uma ciência é que sente a premência das questões [mundanas]. Todo historiador das ciências sabe até que ponto os problemas pessoais, as experiências intelectuais, as necessidade e esperanças de uma época determinam a orientação e o interesse da ciência e da investigação. [...] Isso não significa que se menospreze ou se limite o rigor metodológico da ciência moderna. As denominadas ciências hermenêuticas ou ciências do espírito estão sujeitas aos mesmos critérios de racionalidade crítica que caracteriza o método de todas as ciências, embora seus interesses e procedimentos substancialmente diversos dos que animam as ciências naturais." A hermenêutica como tarefa teórica e prática (1978), VMc, p 368.

17 "ya desde su origen histórico el problema de la hermenéutica va más allá de las fronteras impuestas por el concepto de método de la ciencia moderna. Comprender e interpretar textos no es sólo una instancia científica, sino que pertenece con toda evidencia a la experiencia humana del mundo. En su origen el problema hermenéutico no es en modo alguno un problema metódico. No se interesa por un método de la comprensión que permita someter los textos, igual que cualquier otro objeto de la experiencia, al conocimiento científico. Ni siquiera se ocupa básicamente de constituir un conocimiento seguro y acorde con el ideal metódico de la ciencia. Y sin embargo trata de ciencia y trata también de verdad. Cuando se comprende la tradición no sólo se comprenden textos, sino que se adquieren perspectivas y se conocen verdades. Qué clase de consiento es éste, y cuál es su verdad?" VM, p 23.

18 Mundo como linguagem e sensus comunis: VMc, p 135-136, 176 
Ainda que tenha sido Heidegger quem fixou os aspectos existenciais desse entendimento, ${ }^{19}$ os ecos da indissociabilidade entre ser e pensar já se encontravam na radical historicidade do espírito da filosofia de Hegel (a rigor, residem em Parmênides, mas agora não é necessário ir tão longe) e permanecem nas noções de mundo da vida formuladas por Dilthey ${ }^{20} \mathrm{e}$ Husserl ${ }^{21}$ também. Embora esses dois últimos estivessem às voltas com os problemas da objetividade científica; e cada um a seu modo tentasse estabelecer as possibilidades de os homens emitirem juízos objetivos e verdadeiros quer numa crítica da razão histórica quer através da intencionalidade da consciência. Entretanto, mesmo que Gadamer, seguindo os passos da ontologia de Heidegger, marcasse a distância entre a sua hermenêutica filosófica e o problema da compreensão tal como apareceu no historicismo ou na fenomenologia, convém não subestimar a forte continuidade existente entre todos eles. ${ }^{22}$ Afinal, essa marcação de distância teórica não era unilateral, pois tanto revelava familiaridade quanto (exatamente por isso ${ }^{23}$ ) retraçava os vínculos históricos da tradição intelectual a qual Gadamer pertencia. ${ }^{24}$

19 Heidegger, Ser e Tempo, (§12) p. 96: "[...] , o ser-no-mundo não é uma 'propriedade' que a presença [dasein] à vezes apresenta e outras não, como se pudesse ser igualmente com ela ou sem ela. O homem não 'é' no sentido de ser e, além disso, ter uma relação com o mundo, o qual por vezes the viesse a ser acrescentado. A pre-sença nunca é 'primeiro' um ente, por assim dizer, livre de ser-em que, algumas vezes, tem gana de assumir uma 'relação' com o mundo. Esse assumir relações com o mundo só é possível porque a pre-sença, sendo-no-mundo, é como é. Tal constituição do ser não surge do fato de, além dos entes dotados de caráter da pre-sença, ainda se darem e depararem com ela outros entes, os simplesmente dados. Esses outros entes só podem deparar-se 'com' a pre-sença na medida em que conseguem mostrar-se, por si mesmos, dentro de um mundo."

20 'El saber está ahí; está, sin reflexión, ligado a la vida', dice Dilthey. Es la misma reflexividad inmanente de la vida que según Dilthey, está en la base de la experiencia vivida que tenemos del significado. [...] esto que llamamos sentido de la vida se forma también, incluso ante toda objeción científica, es una panorámica natural de la vida sobre sí misma se encuentra objetivada en la sabiduría de los proverbios y de los mitos, pero sobre todo en las magistrales obras de arte." $\mathrm{CH}, \mathrm{p}$ 60-61.

21 Husserl, nas Meditações cartesianas (§49), sustentou que a fonte da objetividade radica numa comunidade egoíca cujos membros tanto experimentam e confirmam reciprocamente suas existências quanto mutuamente estabelecem e conferem realidade aos seres e haveres do mundo. A objetividade, portanto, é uma conquista constituída nesse comércio dialógico e intersubjetivo que eternamente define, valida e corrige os predicados e as propriedades da chamada realidade. Na Sociologia, os impactos desse entendimento se encontram em The social construction of reality, livro de inspiração schutziana que Peter Berger e Thomas Luckmann publicaram em 1966. Esse ponto foi explorado em: N.CÔRTES, Álvaro Vieira Pinto. A realidade como construção dialógica e temporal. (prelo)

22 "Comprender no es un ideal resignado de la experiencia vital humana en la senectud del espíritu, como en Dilthey, pero tampoco como en Husserl, un ideal metódico último de la filosofía frente a la ingenuidad del ir viviendo, si que por el contrario, es la forma originaria de realización del estar ahí [dasein], del ser-en-el-mundo." VM, p 324 [... "En cuanto que Heidegger resucita el tema del ser y rebasas con ello a todo la metafísica anterior — y no solo a su exacerbación en el cartesianismo de la ciencia moderna y de la filosofía trascendental —, gana frente a las aporias del historicismo una posición fundamentalmente nueva. El concepto de la comprensión no es ya un concepto metódico como en Droysen. La comprensión no es tampoco, con en el intento de Dilthey de fundamentar hemenéuticamente las ciencias del espíritu, una operación que seguiría, en dirección inversa, al impulso de la vida hacia la idealidad. Comprender es el carácter óntico original de la vida humana misma." VM, p 325

23 Vale lembrar que tradições e linhagem de pensamento não são ofertas deixadas pelo passado que ganham vôo próprio e saem por aí atravessando gerações. O traçado de uma tradição filosófica revela um esforço consciente e deliberado de cada momento presente para interpretar e (re)constituir seu próprio caminho de formação intelectual. Portanto, é na atualidade desse gesto que, primeiro, ocorre uma definição do desenrolar temporal das tradições - e isso tanto pode incluir quanto excluir elos eventualmente pertencentes —, e depois, também é quando acontece a inscrição daquele que, ao configurá-la, nela se reconhece. Além de VM, sobre tradições e gerações, ver: MANNHEIM, Karl. O problema das gerações. In: Sociologia do Conhecimento. (II vol) Porto: Rés, s/d e também HOBSBAMW, Eric. A invenção das tradições. Rio de Janeiro: Paz e Terra, 1984.

24 VM, p 27, 285, 292, 299 e seguintes. 
Tais vínculos são observáveis no próprio título de sua obra. A princípio intitulada apenas de Linhas fundamentais de uma hermenêutica filosófica, Verdade e Método ganhou seu nome final por sugestão do editor que tentava conciliar uma alusão à Poesia e Verdade (1811), a última publicação de Johann Wolfgang Von Goethe, com a tradição hermenêutica. Gadamer chegou a ventilar a possibilidade de Entender e Acontecer, ${ }^{25}$ mas desistiu em favor de claramente inscrever seu livro numa tradição consagrada - embora aí, insisto, também houvesse ruptura e estranheza. Sua opção agregou ao título uma série de efeitos sutis, porém notáveis. Primeiro, a dualidade e a sonoridade dos nomes confirmavam a sugestão contida na publicação de Goethe. Poesia encerra uma expressão da verdade ${ }^{26}$ e consiste numa manifestação do espírito que reúne, condensando, os territórios da arte e da linguagem (ambos respectivamente explorados na primeira e na ultima parte de Verdade e Método). Depois, mesmo tendo sido deixada no subtítulo, a expressão "fundamentos de uma hermenêutica" resgatava, ou como prefere Grondin, provocava, ${ }^{27} \mathrm{o}$ antigo legado de exegese bíblica, jurídica ou filológica - uma tradição de sabedoria compreensiva para qual o autor pretendia retornar. E por fim, desconcertantemente, a palavra "método" se de um lado era alusiva aos domínios da ciência (território contemplado na segunda parte do livro), de outro, também remetia diretamente aos escritos de Schleiermacher que tentaram converter a antiga tradição hermenêutica em um sistema universal e abstrato de regras para a correta compreensão. ${ }^{28}$ E esse era justamente o pomo da discórdia.

Se isso fez a alegria de grande parte dos seus comentadores, também resultou numa fortuna crítica marcada pela reiterada exigência de ajustes e esclarecimentos. E Gadamer não fugiu às admoestações dos seus leitores. (A bem da verdade, o público só saiu ganhando, pois ele nos brindou com uma coleção de pequenos e densos ensaios explicativos de sua hermenêutica filosófica). Mas, a despeito da produtividade desses debates, o nome Verdade e Método mantém um atrito surdo face aos seus próprios postulados teóricos. ${ }^{29}$ Se o compararmos com Ser e Tempo, neste caso, a discrepância é inexistente. Afinal, a tese fundamental desta obra sustenta firmemente a cópula enunciada pelo título. Quer dizer: em Heidegger, ser

25 Título que traduz a seguinte concepção: "La comprensión misma se mostró como un acontecer, y filosóficamente la tarea de la hermenéutica consiste en inquirir qué clase de comprensión, y para qué clase de ciencia es ésta que es movida a su vez por el propio cambio histórico." VM, p 380.

26 "También la experiencia estética es una manera de autocomprenderse. [...] el arte es conocimiento, y que la experiencia de la obra de arte permite participar en este conocimiento." VM, p 138 e 139. Cf também GADAMER, H.G. Quem sou eu, quem és tu? Rio de Janeiro: EdUERJ, 2005 e Benedito NUNES. Hermenêutica e poesia. Belo Horizonte: Editora UFMG, 1999.

27 GRONDIN, Hans Georg Gadamer: una biografia, p 377.

$28 \mathrm{VM}, \mathrm{p} 303$.

29 "Gadamer's book could almost have been called Against Method or Beyond Method: he is concerned with a 'pre-understanding' which makes possible, but at same time sets limits to, any interpretative technique." William OUTHWAITE. Hans-Georg Gadamer. In The return of grand theory in the Human Sciences. SKINNER, Q (org). Cambridge: Cambridge University Press, 1985, p 24. 
é tempo. Raciocínio cuja analogia não se aplicaria ao entendimento da hermenêutica gadameriana. Porque, a rigor, nem o método é caminho, fundamento ou morada da verdade; nem verdade consiste num substantivo feminino singular que guarda clara e inequívoca unidade de sentido.

\section{3.}

Breve e resumidamente, o argumento central de Verdade e Método postula que o problema da compreensão hermenêutica radica na faticidade do dasein ${ }^{30}$ — isto é, reside no mundo da vida - e, portanto, precede ao solilóquio de uma consciência pura ensimesmada. Nesse sentido, ao contrário do que disseram todas as modernas filosofias da consciência (leia-se: Descartes, Kant, Hegel, Dilthey, Husserl), os esforços cognitivos que fundamentam a inteligência compreensiva dispensam a exigência de uma incursão teorética de natureza epistemológica para repousar na própria experiência mundana, ou se o leitor preferir: na realidade histórica, na experiência, no tempo, na tradição.

Em outras palavras, a hermenêutica gadameriana rejeita a pretensão de verdade contida no método científico porque entende que a consciência subjetiva não é o fiat inaugural da empresa cognoscente. ${ }^{31}$ Quer dizer, não existe um cogito absoluto ou uma razão transcendental que, instalados como princípios primeiros da inteligibilidade do mundo, ou declara "penso, logo existo";32 ou estabelece a crítica aos limites da razão para, a priori da experiência, definir todas as condições de possibilidade do conhecer, do juízo estético ou do agir moralmente orientado. Para Gadamer, essas atitudes teóricas são insuficientes como fundamentos da inteligência compreensiva, pois, na medida em que desconhecem a historicidade da consciência e (pior ainda) ignoram o caráter histórico das suas próprias incursões epistêmicas, acabam promovendo uma fuga metafísica que imagina ser capaz de se despojar dos apelos da realidade e da tradição, desenraizando a consciência do mundo.

Expressão do vínculo (mas guardião da distância) entre sujeito e objeto do conhecimento, o método científico não foi somente uma fórmula eficaz

30 Para Heidegger, "Não é na ciência historiográfica que se deve buscar a história. Mesmo que o modo científico e teórico de tratar o problema da 'história' não vise apenas a um esclarecimento epistemológico (Simme/) da apreensão histórica, nem a uma lógica da construção conceitual da exposição histórica (Rickert), mas também se oriente pelo 'lado do objeto', mesmo assim, nesse tipo de questionamento, a história só se faz acessível, em princípio, como objeto de uma ciência. Com isso, deixa-se de lado o fenômeno fundamental da história, o qual está à base e precede toda possível tematização historiográfica. É somente a partir do modo de ser da história, a historicidade, e de seu enraizamento na temporalidade que se poderá concluir de que a maneira a história pode se tornar objeto possível da historiografia." [...] "A análise da historicidade da pre-sença [dasein] busca mostrar que esse ente não é 'temporal' porque se 'encontra na história' mas, ao contrário, que ele só existe e só pode existir historicamente porque, no fundo de seu ser, é temporal." HEIDEGGER, op. cit., (ST), vol. II, p 180-181 Cf. particularmente: VM, p 321-323

31 VM, p 319

32 Jean Paul Sartre (1905-1980) compartilha das mesmas matrizes filosóficas de Gadamer. Ele formulou uma das máximas do existencialismo e, invertendo os termos da proposição cartesiana, declarou: "existo, logo penso". J. SARTRE, P. O existencialismo é um humanismo. In: Os Pensadores, São Paulo, Abril, 1973, p12. 
que a modernidade encontrou para enfrentar o ceticismo assegurando indubitabilidade aos nossos juízos. No limite, sua assertividade repousa sobre um insulamento da consciência que, ao encapsular a subjetividade num suposto reino de pureza e controle procedimental, também promoveu um divórcio da realidade. Para os teóricos das ciências do espírito que pretenderam aplicar este modelo de método e objetividade na observação do mundo da mobilidade histórica - mundo que, desde a Ciência Nova (1744) de Vico, passou a ser positivamente considerado como reino da transitoriedade temporal habitado por sujeitos inteligentes e livres e, portanto, ontologicamente idênticos aos seus observadores ${ }^{33}$ - tal ensimesmamento cognitivo resultou em fecundos, mas inconclusos debates epistemológicos. ${ }^{34}$ Perplexos, neokantianos e historicistas não apenas se enredaram numa aporia que indagava sobre as condições de possibilidade da compreensão da alteridade temporal - Como compreender a singularidade do passado, considerando que sua dessemelhança pode tornar-se um interdito a tal pretensão de conhecimento? — como também acentuaram o insulamento solipsista. E isso porque sugeriram que o conhecimento da história consistia em um encontro entre dois sujeitos singulares, isto é, um diálogo compreensivo entre duas consciências ímpares, separadas por um abismo temporal e igualmente prisioneiras dos seus respectivos e distintos mundos históricos. (As biografias de indivíduos extraordinários expressam a produção historiográfica desta concepção de História).

Concorrendo com o ideal científico metódico, que exigia um sujeito cognoscente capaz de contrição moral-intelectual visando despojar-se dos apelos mundanos, a moderna concepção de tempo como linearidade ordenada causalmente através de unidades temporais sucessivas e discretas - espécie de fila indiana que organiza sequencialmente passado, presente, futuro — conduziu a uma crescente percepção (e autoconsciência) da finitude dos períodos históricos e converteu o diálogo entre as épocas numa façanha

33 À sombra de Descartes, Vico comparou a Ciência Nova à Geometria e estabeleceu o fundamento da cognição histórica sobre o principio de identidade entre a coisa conhecida e o sujeito que conhece entre o ser (observado) e o pensar (que o contempla). Argutamente, ele mobilizou os mesmos termos da proposição cartesiana, invertendo-a para afirmar a impossibilidade de conhecimento sobre a natureza (pois é criação divina). A História, ao contrário, seria cognoscível justamente por ser criatura dos feitos humanos. Respondendo a tal questão, Gadamer salientou que Esto no significa de ningún modo que el cognoscente y lo conocido sean modo de ser homogéneos, y que el método de las ciencias humanas se fundamente en esta homogeneidad. Esto hária de lo histórico una psicologia. La correlación común que posee el conocimiento y lo conocido, este tipo de afinidad que liga el uno al outro, no se fundamenta en la equivalencia de su modo de ser, sino sobre esto que es este modo de ser. Esto significa que ni el cognoscente ni el conocido estan onticamente y simplemente subsistentes, sino que son historicos, es decir, que tienen el modo de ser de la historicidad. CH, p 75-76. .Para uma tipologia do argumento do "conhecimento do criador", cf: DOMINGUES, Ivan. Epistemologia das ciências humanas. São Paulo: Loyola, 2004.

34 Sobre historicismo, cf: ANTONI, Carlo. L'historisme. Paris: Droz, 1963. Raymond ARON. Dimensiones de conciencia historica. México, Fundo de Cultura Económica, 1984.; La philosophie critique de l'histoire. Paris, Vrin, 1964.; Manuel CRUZ. El historicismo. Barcelona, Montesinos, 1981.; Francisco FALCON. Historicismo: a atualidade de uma questão aparentemente inatual. Tempo. Rio de Janeiro, n. 4, 1997, p 5-20. ; Georg IGGERS. The german conception of history. Wesleyan University Press, 1983.; MEINECKE, Friedrich. El historicismo y su génesis. México, FCE, 1982.; REILL, Peter Hanns. The german enlightenment and the rise of historicism. University of California Press, 1975.; REIS, José Carlos. Historia \& teoria. Historicismo, modernidade, temporalidade e verdade. Rio de Janeiro: Editora FGV, 2003.; WEHLING, Arno. A invenção da história. Estudos sobre o historicismo. Rio de Janeiro, EDUFF, 1994. 
quase inexeqüível. É importante observar, contudo, que tais alterações cognitivas não foram apenas e meramente coincidentes. Apesar de impremeditadas, elas convergiram para formar o imaginário e a constelação intelectual da modernidade ${ }^{35}$ tanto porque configuraram como uma nova percepção da experiência temporal (Koselleck vai falar em crise da história magistra vitae e "inversão do horizonte das expectativas temporais"36) quanto porque, reagindo a essa novidade histórica, formularam uma teoria do conhecimento que se adequava e correspondia às propriedades ônticas dessa realidade temporalmente fragmentada, confirmando-Ihe a visão de mundo.

Convém esclarecer, porém, que nem de longe pretendo sugerir qualquer dialética entre pensamento filosófico "em seu" contexto histórico. Repito: Verdade e Método rejeita o dualismo consciência e realidade que alimenta a oposição entre pensar e ser. ${ }^{37} \mathrm{E}$ não obstante possa ser aproximada da sociologia do conhecimento tal como concebida por Karl Mannheim (18931947) — de resto, autor que compartilha das mesmas matrizes teóricas que Gadamer $^{38}$ —, aquilo que a démarche gadameriana analisa teoricamente, narra historicamente e expressa teticamente é o jogo ${ }^{39}$ através do qual uma "tradição de experiência pensante" 40 constituiu a realidade do mundo dos homens.

Nesse registro, as visões do triunfalismo iluminista e do saudosismo romântico foram similares. Invertidamente, eram sócios da mesma filosofia da História ${ }^{41}$ que, ora por progresso ora por decadência, confirmava o aprofundamento da distância temporal. E uma vez que esse fosso passou a ser valorizado como diversidade e singularidade histórica - "todas as épocas estão próximas de Deus", para lembrar a máxima de Ranke — também foi alargado a despeito e por causa da "docilidade compreensiva" do histori-

35 Cf TAYLOR, C. Superar a epistemologia. Argumentos filosóficos. São Paulo: Loyola, 2000, p 19

36 KOSELLECK, Reinhart. Futuro Pasado. Barcelona, Paidós, 1993. Para explorar os vínculos entre ambos cf.: KO SELLECK, R. Histórica y hermenéutica. \& GADAMER, H. G. Histórica y lenguaje: una resposta. Barcelona. Paidós 1997. Ver também: JASMIN, Marcelo. História dos conceitos e teoria político social: referências preliminares. Revista Brasileira de Ciências Sociais (20) 57, fev. 2005, p 27-38; RAUTER, Ana Luiza. A História e o "dialogo que somos": a historiografia de Reinhart Koselleck e a hermenêutica de Hans-Georg Gadamer. Rio de Janeiro: PUC-Rio (dissertação de mestrado), 2004

37 Muito embora Heidegger tenha formulado o termo dasein para se despojar do peso metafísico implícito nas expressões cogito, razão, espírito, consciência etc..., Gadamer mantém o uso do conceito consciência. Suas razões estão em VMc, p 18.

38 HEKMAN, Susan. Hermenêutica e Sociologia do Conhecimento. Lisboa: Edições 70, 1990.

39 Em Gadamer, a experiência do jogo é um dos mais poderosos recursos conceituais mobilizados para enfrentar e dissolver o caráter representacional ou mimético da arte, das ciências, da linguagem. VM, p 143, 526 ; VMc, p 135.

40 Tangenciando esse aspecto, eis a crítica de Gadamer à história dos conceitos: "Assim, a dimensão hermenêutica afeta especialmente o trabalho milenar do conceito filosófico. Como tradição de uma experiência pensante, deve ser compreendida como um único grande diálogo, no qual todo presente participa sem poder controlar superiormente ou dominar criticamente. [...] As palavras que servem de conceitos, cunhadas e transmitidas nela pela filosofia, não são marcas e sinais fixos que designam algo unívoco como acontece no sistema de símbolos da matemática, da lógica e em suas aplicações. As palavras brotam do movimento comunicativo da interpretação que o homem faz do mundo, e que se dá na linguagem. Movidas e transformadas por esta interpretação, as palavras se enriquecem, alcançam novos contextos que recobrem os antigos, resguardam-se num quase esquecimento para tornar à vida em idéias novas e questionadoras." VMc, p 137

41 VM, p 340 e seguintes. VMc, p 120. 
cismo. ${ }^{42}$ Em outras palavras, as teorizações sobre os esforços simpáticos, filológicos ou psicológicos necessários para que o intérprete ultrapassasse sua própria historicidade e compreendesse o passado não passavam de elucubrações metódicas que repousavam justamente sobre a suposição da incomensurabilidade dos tempos, sancionando-a irremediavelmente.

No que diz respeito às ciências do espírito, os passos de Gadamer em Verdade e Método expressam uma reação crítica que dá seqüência histórica, mas dissolve e ultrapassa tais aporias do historicismo. Nesse sentido, ele escreveu:

El tiempo ya no es primariamente un abismo que hubiera de ser salvado porque por sí mismo sería causa de división y lejanía, sino que es en realidad el fundamento que sustenta el acontecer en el que tiene sus raíces el presente. La distancia en el tiempo no es consecuencia algo que tenga que ser superado. Este era más bien el presuposto ingenuo del historicismo: que había que desplazarse al espíritu de la época, pensar en sus conceptos y representaciones en vez de en las propias, y que sólo así podría avanzarse en el sentido de una objetividad histórica. Por el contrario de lo que se trata es de reconocer la distancia en el tiempo como una posibilidad positiva y productiva del comprender. No es un abismo devorador, sino que está cubierto por la continuidad de la procedencia y de la tradición, a cuya luz se nos muestra todo lo transmitido. ${ }^{43}$

Para além do historicismo com seus problemas metodológicos, ${ }^{44}$ a consciência hermenêutica entende-se exatamente como aquela que se sabe enraizada na mobilidade da realidade temporal. ${ }^{45} \mathrm{E}$, no entanto, ao invés de converter tal autoconsciência da sua transitoriedade e do seu próprio engajamento em empecilhos que interditam o reconhecimento da realidade histórica, percebe que é exatamente aí onde se encontram todas

42 Existem indisfarçáveis traços de arrogância intelectual nessa docilidade compreensiva. Ela supõe uma hierarquia de competências cognitivas que confere prerrogativas ao presente e rejeita de antemão a real validade do conteúdo de verdade contido nos textos passados. No limite, tal esforço compreensivo relega o passado a uma situação de menoridade intelectual (no plano metodológico, é exemplar dessa presunção cognitiva a máxima que diz que as fontes primárias são destituídas de fala, salvo se indagadas pelo historiador!), pois degrada suas crenças transformando-as em valores (ideologias ou mithos pré-científicos e pré-lógicos) sem razoabilidade atual. A propósito, cf. particularmente VM, p 374. Ver também: VM, p 340, 350, 632; VMc, p 141

$43 \mathrm{VM}, \mathrm{p} 367$

44 No plano teorético, trata-se de um movimento que converteu a preocupação epistêmica numa ontologia. Nas palavras de Gadamer: "O problema hermenêutico alcançou sua radicalização filosófica quando as idéias de Dilthey (e Kierkegaard) passaram a fundamentar a filosofia existencial. Foi quando Heidegger formulou o conceito de uma 'hermenêutica da faticidade', [...] Nesse momento, alcançou-se um ponto no qual o caráter instrumentalista do método, presente no fenômeno hermenêutico teve de reverter-se à dimensão ontológica. 'Compreender' não significa mais um comportamento do pensamento humano dentre outros que se pode disciplinar metodologicamente, conformando assim a um procedimento científico, mas perfaz a mobilidade de fundo da existência humana." Hermenêutica clássica e hermenêutica filosófica (1968). VMc, p 125.

45 "Un pensamiento verdaderamente histórico tiene que ser capaz de pensar al mismo tiempo su propia historicidad." [...] ".la autocrítica de la conciencia histórica llega al cabo a reconocer movilidad histórica no sólo en el acontecer sino también en el propio comprender. El comprender debe pensarse menos como una acción de la subjetividad que como un desplazarse uno mismo hacia un acontecer de la tradición, en el pasado y el presente se hallan en continua mediación." VM, p 370 e 360. 
as condições de possibilidade para a compreensão do passado. ${ }^{46}$ Seus pré-conceitos, portanto, são intelectualmente produtivos. ${ }^{47}$ Eles instalam, constituem e lançam a consciência no mundo. "Uma hermenêutica filosófica, escreveu o autor, haverá de concluir que o compreender só é possível quando aquele que compreende coloca em jogo seus próprios preconceitos. A contribuição produtiva do interprete é parte inalienável do próprio sentido do compreender." ${ }^{8}$ Nesse sentido, ao invés de macularem a objetividade ou contaminarem a clareza das suas intenções cognoscentes, efetivamente oferecem topoi cognitivos (nos termos de Thomas Kuhn: paradigmas ${ }^{49}$ ) e horizontes temporais a partir dos quais se pode visar o passado. ${ }^{50} \mathrm{Em}$ outras palavras, os pré-conceitos são aberturas da realidade histórica ${ }^{51}$ que inauguram os descaminhos do método hermenêutico ${ }^{52}$ oferecendo ocasião para o desfiar de uma senda temporal.

\section{4.}

Para os historiadores — homens e mulheres cujo dever profissional é narrar a verdade dos fatos passados —, há importantes impactos envolvidos na hermenêutica gadameriana. Muito antes de resumir uma querela acerca dos protocolos procedimentais daquilo que, ironicamente, se poderia chamar de "regras do método histórico", ela repeliu a pretensão de cientificidade da compreensão e, alterando o atual estatuto epistemológico do conhecimento histórico, ${ }^{53}$ comparou a História à filosofia prática. Quer dizer,

46 "La historicidad del historiador y su inserción en una coexistencia social no prohíben que se elabore la ciencia histórica, son, por el contrario, las condiciones de su posibilidad." LYOTARD, Jean-François. La fenomenologia. Buenos Aires, Editorial Universitaria de Buenos Aires, 1960, p 14.

47 En realidad no es la historia la que nos pertenece, sino que somos nosotros los que pertenecemos a ella. Mucho antes de que nosotros nos comprendamos a nosotros mismos en la reflexión, nos estamos comprendiendo ya de una manera autoevidente en la familia, la sociedad y el estado en que vivimos. La lente de la subjetividad es un espejo deformante. La autorreflexión del individuo no es más que una chispa en la corriente cerrada de la vida histórica. Por eso los prejuicios de un individuo son, mucho más que sus juicios, la realidad histórica de su ser VM, p 344

48 VMc, p 132 e 133

49 Em VMc, p 138, encontram-se alguns comentários de Gadamer sobre as idéias de Thomas Kuhn.

50 "la pertenencia a la tradición es una de las condiciones de la comprensión espiritual-científica. [...] Evidentemente no se trata de una condición restrictiva de la comprensión sino más bien de una de las condiciones que la hacen posible. La pertenencia del intérprete a su texto es como la del ojo a la perspectiva de un cuadro. Tampoco se trata de que este punto de mira tenga que ser buscado como un determinado lugar para colocarse el él, sino que el que comprende no elige arbitrariamente su ponto de mira sino que su lugar le está dado con anterioridad." VM, p 401.

51 "Deixando-se inteiramente de lado se estão disponíveis as fontes suficientes para uma apresentação historiográfica do passado, o caminho para o passado deve estar aberto, no sentido de retorno historiográfico. Não é, contudo, evidente se isso acontece e como isso é possível." HEIDEGGER. Ser e Tempo, vol. II, p 200. Sobre projeto como preconceito, cf: VMc p 75-6,

52 Método significa literalmente caminho ou travessia. (Méthodos. de metá 'atrás, em seguida, através' + hodós 'caminho'. Dicionário Eletrônico Houaiss da Língua Portuguesa 1.0, São Paulo: Objetiva, 2001) Gadamer define seu moderno significado nos seguintes termos: "O ideal de conhecimento pautado pelo conceito de método consiste em se poder trilhar um caminho cognitivo de maneira tão consciente que se torna possível refazê-lo sempre. Méthodos significa 'caminho de seguimento'. Metódico é poder-seguir sempre de novo o caminho já trilhado e é isto o que caracteriza o proceder da ciência" VMc, p 61

53 Atualmente, e pelo menos desde a década de 1980, este estatuto científico está sob suspeição. Os debates historiográficos contemporâneos (dentro do quais Verdade e Método é uma importante peça argumentativa) estão 
Gadamer aproximou o conhecimento do passado da prhonesis (prudência) - juízo prático que reúne as virtudes do homem ponderado, experiente, cauteloso, sensato etc. - saber usualmente é necessário para o equilíbrio e a boa condução da vida em comum. Em 1980, refinando as suas já consagradas ambições filosóficas, ele reafirmou: "Tentarei mostrar que a filosofia prática de Aristóteles - e não o conceito moderno de método e de ciência - representa o único modelo viável para formarmos uma idéia adequada das ciências do espírito." 54

Com isso, concedeu ao conhecimento histórico a mesma dignidade humanista que foi paulatinamente esquecida e degradada pelas controvérsias cientificistas e metodológicas. $E$, insistindo na diferença de ideais cognitivos entre as ciências da natureza e as do espírito, afirmou que "o essencial das 'ciências do espírito' não é a objetividade, mas a relação prévia com o objeto". ${ }^{55}$ Esse argumento ultrapassa as questões em torno da polarização objetividade versus subjetividade, pois seu principal aspecto, incidindo sobre historicidade da inteligência compreensiva e enfatizando o engajamento mundano do pensar, converte tal pertencimento numa exigência epistêmica, isto é, no ponto zero do conhecimento histórico. Em outras palavras, o fundamento da compreensão reside no pertencimento do intérprete a uma dada tradição, pois, nas ciências do espírito, a participação precede a teoria. ${ }^{56}$

A História, nesse diapasão, deixa de ser concebida como ciência - quiçá como arte ou filosofia - e passa a ser aproximada de um tipo de sabedoria mundana que, ao arrepio da contemplação teorética, traduz-se como experiência (ouso dizer, maturidade) e encontra a fonte da sua primazia intelectual na opinião comum (doxa). Gadamer estava às voltas, portanto, com as indagações da tradição filosófica que Aristóteles deslindou na Ética a Nicomaco ${ }^{57}$ e que, grosso modo, se cingiam a definir a natureza dessa disposição prática. Então, todo o problema consistia em qualificar essa inteligência que: a) não se pretende desinteressada ou axiologicamente neutra, pois embora tenda à universalidade do bem comum, se sabe parte envolvida; b) não é uma ciência (episteme), pois não repousa seus princípios sobre regras abstratas universais necessárias; c) nem é manifestação artística, uma vez que visa a ação. Virtude intelectual, ${ }^{58}$ a prhonesis é a habilidade que

vazados por atitudes irônicas ou céticas que renunciaram às explicações totalizadoras e às certezas científicas. Entre outros, ver IGGERS, G. La ciência histórica em el siglo XX. Barcelona: Idea Books, 1995. $2^{\mathrm{a}}$ edição.

54 VMc, p 369

55 VMc, p 374

56 VMc, p 378

57 Aqui está em jogo a montagem de uma bela rede de temporalidades em que releituras dos passados promovem metamorfoses na tradição. Sobre a originalidade da apropriação gadameriana de Aristóteles, cf. BERNSTEIN, R. Beyond objectivism and relativism. Philadelphia, University of Pennsylvania Press, 1983, p 39. Sobre a valorização da tradição no próprio Aristóteles, que procura suas fontes na sabedoria popular em detrimento do intelectualismo platônico, ver AUBENQUE, P. A prudência em Aristóteles. São Paulo: Discurso Editorial, 2003, p 46, 84, 89.

58 AUBENQUE, op. cit., p 87 
permite julgar, discernir, calcular e escolher os justos meios para a realização da ação correta. Ela é o traço que distingue e valoriza o homem que, na premência da decisão, é capaz de identificar e fazer a coisa certa.

Muito bem. Quando Gadamer evocou a Aristóteles, aproximando o conhecimento histórico dessa forma de inteligência prática, tanto apontava para uma revalorização do caráter civilizacional dos saberes da História quanto aquilatava a importância da responsabilidade intelectual e social do historiador. ${ }^{59}$ Todavia, também deixava escapar alguns problemas metodológicos bastante embaraçosos.

Considerando que traduz em sabedoria o acervo das experiências de uma vida, a prudência é um tipo de conhecimento incomunicável e intransferível. Singular, ela pertence somente àquele que individualmente e por si mesmo, através de um laborioso e paciente processo de amadurecimento, soube, pôde e quis conquistá-la. Seu conhecimento não é passível de ser transferido e apreendido através de protocolos institucionalizados. Antes, o processo de sua transmissão exige tempo (em todos os sentidos). "É preciso tempo para aceder à prudência: tempo que não permite precipitação, nem mesmo previsão". ${ }^{60}$ Quer dizer, não se trata apenas de transferir um cabedal conceitual ou doutrinário a ser assimilado através de exercícios de fixação (tal como na Matemática). Prudência não se ensina; sua transmissão, porém, envolve a repetição da experimentação da vivencia em um processo de aprendizagem intransferível de formação (bildung) do costume - entenda-se: hábito, estilo, caráter.

A metodologia científica não conhece esses embaraços. Sistematizada num conjunto de regras protocolares, ela é formal e facilmente transmitida. Isso a torna cognitivamente democrática - embora esta grandeza seja também a sua miséria (fato que não passou despercebido por Dilthey ${ }^{61}$ ).

Em Verdade e Método, Gadamer não pretende insinuar qualquer apreço esnobe ou aristocrático pelo saber da História. Ao contrário. Afinal, ao confundir o conhecimento do passado com a sabedoria prudencial, nos fez pensar que ambos (ao invés de exigirem cálculo procedimental) consistem em, demandam por, transmitem-se através e finalmente expressam o processo dialógico e temporal que conforma a cultura de uma tradição. Como a prudência, a História não requer método. Ambas descrevem os descaminhos do tempo que cada nova geração deve aprender a "des-esquecer".

59 VMc, p 46

60 AUBENQUE, op cit, p 100

61 A obsessão da Escola Histórica, sobretudo de Dilthey, [mas] também de Droysen, [...] é como fazer com que indivíduos em geral, que ele chama de 'medíocres', os indivíduos pouco geniais, possam fazer história, sociologia, psicologia, literatura, sem dizer 'tolices', porque os gênios têm a capacidade de perceber, na produção singular, o universal que nelas se esconde; [...]. Mas como nem todos são gênios [...] precisamos dar regras para a média, as regras tem que ser dadas para os que são menos bons na análise dos objetos da cultura humana, e a teoria da 'compreensão' pretende elaborar bases epistemológicas, lógicas e metodológicas para servir de 'muleta'à media do universo de estudiosos, nos diversos campos das ciências humanas." STEIN, E. Racionalidade e existência. Porto Alegre; LP\&M, 1988, p 41. 


\section{Quadro sinóptico sobre algumas noções de História em Verdade e Método}

\begin{tabular}{|c|c|c|}
\hline Noções & Consciência metódica & Consciência hermenêutica \\
\hline $\begin{array}{l}\text { Compreensão } \\
\text { histórica }\end{array}$ & $\begin{array}{l}\text { Como diálogo entre duas consciências } \\
\text { insuladas no tempo (esforço simpático) } \\
0 \text { presente compreende melhor } 0 \\
\text { passado }\end{array}$ & $\begin{array}{l}\text { É continuação de um diálogo temporal / gera- } \\
\text { cional iniciado antes do historiador } \\
\text { Cada época compreende um passado diferente, } \\
\text { não mais nem melhor. }\end{array}$ \\
\hline Método & $\begin{array}{l}\text { Realiza-se como evasão solipsista, exigin- } \\
\text { do contrição moral-intelectual e controle } \\
\text { procedimental. }\end{array}$ & $\begin{array}{l}\text { Exige autoconsciência do pertencimento do } \\
\text { ser-no-mundo a uma tradição } \\
\text { (situação hermenêutica) } \\
\text { Realiza-se a partir dos pré-conceitos como } \\
\text { o desfiar de um descaminho histórico } \\
\text { temporal. }\end{array}$ \\
\hline Atitude teórica & $\begin{array}{l}\text { Estabelecer fundamentos e condições de } \\
\text { possibilidade do conhecimento } \\
\text { (epistemologia) }\end{array}$ & $\begin{array}{l}\text { Antes de ser analítica, teoria é participação. A } \\
\text { atitude contemplativa, theoros, realiza-se como } \\
\text { entrega e arrebatamento. }\end{array}$ \\
\hline $\begin{array}{l}\text { Objeto do conheci } \\
\text { mento histórico }\end{array}$ & $\begin{array}{l}\text { Objeto como pólo antagônico ao sujeito } \\
\text { observador }\end{array}$ & $\begin{array}{l}\text { Objeto como percurso temporal constituinte } \\
\text { do sujeito (tradição). VMc, } 81\end{array}$ \\
\hline Realidade histórica & Realidade como dado substantivo & $\begin{array}{l}\text { Realidade como construto temporal e } \\
\text { dialógico }\end{array}$ \\
\hline Tempo & Linearidade temporal e sucessão causal & Rede de temporalidades \\
\hline Passado & $\begin{array}{l}\text { Passado como alteridade temporal. Trata- } \\
\text { se de um tempo findo e ultrapassado }\end{array}$ & $\begin{array}{l}\text { Presente que foi, no passado coexistiram vários } \\
\text { outros tempos. Suas próprias interpretações de } \\
\text { outros passados ainda mais remotos e seus } \\
\text { projetos de futuros, utopias realizadas ou não } \\
\text { (futuros passados perdidos). }\end{array}$ \\
\hline Memória & $\begin{array}{l}\text { Ela entesoura os fatos passados, mas não } \\
\text { é confiável. A verdade resulta do método } \\
\text { e não anamnese }\end{array}$ & $\begin{array}{l}\text { A memória se a-presenta sempre outra e atual. } \\
\text { Ela é histórica e sofre todas as metamorfoses } \\
\text { dos tempos }\end{array}$ \\
\hline Tradição & $\begin{array}{l}\text { Força inercial e conservadora que paralisa } \\
\text { a mudança e o ritmo dos tempos }\end{array}$ & $\begin{array}{l}\text { Realiza-se por gestos criativos e livres de } \\
\text { reconhecimento e transmissão de princípios } \\
\text { civilizacionais. }\end{array}$ \\
\hline História & $\begin{array}{l}\text { Dualismo história rerum gestarum historia } \\
\text { res gestae } \\
\text { Oposição entre conhecimento e fato, } \\
\text { consciência e realidade. }\end{array}$ & $\begin{array}{l}\text { Diálogo que somos nós. } \\
\text { Linguagem transmitida através das gerações, } \\
\text { a história é um idioma do /no mundo. Ela } \\
\text { não é tão-somente uma representação dos } \\
\text { fatos passados, mas consiste num saber } \\
\text { prudencial constitutivo da realidade que reúne } \\
\text { (cons)ciência e experiência (phronesis). }\end{array}$ \\
\hline Arte & $\begin{array}{l}\text { Arte como liberalidade criativa } \\
\text { É uma representação imagética ou ficcio- } \\
\text { nal do mundo } \\
\text { Estética do gênio e do gosto subjetivo }\end{array}$ & $\begin{array}{l}\text { A arte encerra uma verdade. Sua experiência } \\
\text { não é a do gozo estético. Trata-se de pathos e } \\
\text { não da representação de um dado real que a } \\
\text { determina ou antecede }\end{array}$ \\
\hline Linguagem & $\begin{array}{l}\text { A linguagem como locução. Trata-se } \\
\text { de um veículo que enuncia, descreve e } \\
\text { representa e os haveres e seres contidos } \\
\text { na realidade. }\end{array}$ & $\begin{array}{l}\text { Linguagem como colóquio } \\
\text { e processo compartilhado. } \\
\text { Não representa um mundo, simplesmente } \\
\text { encerra tudo o que é. } \\
\text { "O ser que pode ser compreendido é lin- } \\
\text { guagem" }\end{array}$ \\
\hline
\end{tabular}




\section{REFERÊNCIAS BIBLIOGRÁFICAS}

\section{a) Hans-Georg GADAMER}

El problema de la conciencia histórica. Madrid: Tecnos, 1993. Heidegger's ways. Albany: State University of New York Press, 1994.

Histórica y lenguaje: una resposta. Barcelona. Paidós, 1997.

Mis anos de aprendizaje. Barcelona: Herder, 1996.

Quem sou eu, quem és tu? Rio de Janeiro: EdUERJ, 2005

Verdad y Método. Salamanca: Síguime, 1988.

Verdade e Método. Índices e complementos. Petrópolis: Vozes, 2004, $2^{\mathrm{a}}$ edição.

\section{b) Demais autores}

ANTONI, Carlo. L'historisme. Paris: Droz, 1963.

ARON, Raymond. Dimensiones de conciencia historica. México, Fundo de Cultura Económica, 1984.

ARON, Raymond. La philosophie critique de l'histoire. Paris, Vrin, 1964.

AUBENQUE, Pierre. A prudência em Aristóteles. São Paulo: Discurso Editorial, 2003.

BERNSTEIN, Richard. Beyond objectivism and relativism. Philadelphia, University of Pennsylvania Press, 1983.

CALVINO, Ítalo. Por que ler os clássicos. São Paulo: Companhia das Letras, 1993.

CARDOSO, Ciro F. e MALERBA, J. (org) Representações: contribuições a um debate transdisciplinar. Campinas, SP: Papirus, 2000.

CÔRTES, Norma. Álvaro Vieira Pinto. A realidade como construção temporal e dialógica. Bahia, Cadernos CRH (prelo).

CÔRTES, Norma. Fatos, fontes e frutos de uma tradição filosófica. Cronologia bibliográfica selecionada. Disponível em Artes do Tempo www.artesdotempo.hpg.com.br.

CRUZ, Manuel. El historicismo. Barcelona, Montesinos, 1981.

DELACAMPAGNE, Christian. História da Filosofia no século XX. Rio de Janeiro: Jorge Zahar, 1997.

DOMINGUES. Ivan. Epistemologia das Ciências Humanas. São Paulo: Loyola, 2004.

DOSSE, François. La marche dês idées. Histoire dês intellectuels - histoire intellectuelle. Paris: La Découverte, 2003.

FALCON, Francisco. Historicismo: a atualidade de uma questão aparentemente inatual. Tempo. Rio de Janeiro, n. 4, 1997, p 5-20.

GRONDIN, Jean. Hans-Georg Gadamer: una biografia. Barcelona: Herder, 2000.

GRONDIN, Jean. Introdução à hemeneutica filosófica.São Leopoldo: Editora UNISINOS, 1999,

HEIDEGGER, Martin. Ser e Tempo. Petrópolis: Vozes, 1993.

HEKMAN, Susan J. Hermenêutica e Sociologia do Conhecimento. Lisboa: Edições 70, 1990

HOBSBAMW, Eric. A invenção das tradições. Rio de Janeiro: Paz e Terra, 1984.

HOUAISS, A. Dicionário Eletrônico Houaiss da Língua Portuguesa 1.0, São Paulo: Objetiva, 2001.

HUSSERL, Edmund. (1929) Meditações cartesianas. Porto: Rés, s/d.

IGGERS, Georg G. The german conception of history. Wesleyan University Press, 1983.

IGGERS, Georg G. La ciência histórica em el siglo XX. Barcelona: Idea Books, 1995.

INWOOD, Michael. Dicionário Heidegger. Rio de Janeiro: Jorge Zahar, 2002.

JASMIN, Marcelo. História dos conceitos e teoria político social: referências preliminares.

Revista Brasileira de Ciências Sociais (20) 57, fev. 2005, p 27-38.

KOSELLECK, Reinhart. Futuro Pasado. Barcelona, Paidos, 1993.

KOSELLECK, Reinhart. Historia y hermenéutica. In GADAMER, H.G. Histórica y lenguaje: una resposta. Barcelona: Paidós, 1997. 
LYOTARD, Jean-François La fenomenologia. Buenos Aires: Editorial Universitaria de Buenos Aires, 1960.

MANNHEIM, Karl. O problema das gerações. Sociologia do Conhecimento. Porto: Rés, $\mathrm{s} / \mathrm{d}$.

MEINECKE, F. El historicismo y su gênesis. México: Fundo de Cultura Economico, 1982.

MORA, J. Ferrater. Diccionario de Filosofia. Barcelona: Ariel, 1994.

NUNES, Benedito. Hermenêutica e poesia. Belo Horizonte: Editora UFMG, 1999.

OUTHWAITE, William. Hans-Georg Gadamer. The return of grand theory in the Human Sciences. Q. SKINNER (org). Cambridge: Cambridge University Press, 1985.

PALMER, Richard E. Hermenêutica. Lisboa: Edições 70, 1999.

PEREIRA, Luísa Rauter. A História e o "dialogo que somos": a historiografia de Reinhart Koselleck e a hermenêutica de Hans-Georg Gadamer. Rio de Janeiro: PUC-Rio (dissertação de mestrado), 2004.

REILL, Peter Hanns. The german enlightenment and the rise of historicism. University of California Press, 1975.

REIS, José Carlos. Historia \& teoria. Historicismo, modernidade, temporalidade e verdade. Rio de Janeiro: Editora FGV, 2003.

RORTY, Richard. et alii. El ser que puede ser comprendido es lenguaje. Homenaje a HansGeorg Gadamer. Madrid: Editorial Sintesis, 2002.

RORTY, Richard. Philosophy and the mirror of nature. New Jersey: Princeton University Press, 1979.

SARTRE, J.P. O existencialismo é um humanismo. Os Pensadores. São Paulo: Abril, 1973.

STEIN, Ernildo. Racionalidade e existência. Porto Alegre: LP\&M, 1988.

STEINER, Georg. Depois de Babel: questões de linguagem e tradução. Curitiba: Editora da UFRP, 2005.

STEINER, Georg. Lições dos mestres. Rio de Janeiro: Record, 2005.

TAYLOR, Charles. Superar a epistemologia. Argumentos filosóficos. São Paulo: Loyola, 2000.

WEHLING, Arno. A invenção da história. Estudos sobre o historicismo. Rio de Janeiro, EDUFF, 1994.

c) Imagens de Gadamer:

Disponíveis em: www.wenzel-orf.de/html/gadamer.html. (último acesso: jan / 2006) 